\title{
Decision Structuring and Robustness Analysis in Selecting Urban Transit Alternatives
}

Isam A. Kaysi and Mohamed-Asem U. Abdul-Malak American University of Beirut

\section{Abstract}

Public policy-makers in many cities worldwide have recognized the need to seek urban passenger transport solutions in the domain of urban transit systems. However, with the availability of many transit technologies and systems, decision-makers need support in identifying the advantages and disadvantages of each system, and in evaluating their suitability for the specific urban context being considered.

In this article, the Analytical Hierarchy Process (AHP) is proposed as a decision-support methodology for evaluation of urban transit systems. A hierarchy is proposed for the evaluation of system choice, and an illustrative example is presented. The hierarchy reflects overall objectives of transit systems, which include achieving betterment in the urban transport picture and mitigating possible implementation impediments. On the betterment side, the transit system objectives considered in the hierarchy include appropriate level of service and performance, congestion reduction potential, support of economic development, and flexibility. On the other hand, transit system impediment factors comprise system cost, environmental impacts, and implementation and operation barriers. The article demonstrates the value of the proposed approach in decision structuring for selecting among urban transit alternatives and in providing the facility of analyzing the robustness of the decision with respect to various judgments that are made in the selection process. 


\section{Introduction}

Many cities around the world have realized that they cannot satisfy mobility and accessibility needs of their inhabitants by relying solely on transport facilities serving private automobile travel. Recent findings (Newman and Kenworthy 1999) have indicated that automobile-dependent cities are proving to be very costly in economic and environmental terms, and that there is a need to move toward a modal split which is less automobile-oriented. As such, public policy-makers worldwide have recognized the need to seek urban passenger transport solutions in the domain of urban transit systems. However, with the availability of many transit technologies and systems, decision-makers need support in identifying the advantages and disadvantages of each system, and in evaluating their suitability for the specific urban context being considered.

In this article, the AHP is proposed as a decision-support methodology for evaluation of urban transit systems. The proposed approach is quite helpful in decision structuring for selecting among urban transit alternatives due to its flexibility in incorporating a decision hierarchy and associated judgments. Moreover, it facilitates robustness analysis of the transit technology selection decision with respect to various judgments that are made in the selection process.

This article presents a brief description of urban transit systems and their characteristics. It discusses a number of methods that have been utilized in the evaluation of urban transit alternatives, and provides an overview of the AHP. In addition, the hierarchy being proposed for the evaluation of urban transit systems is presented, followed by an illustrative example.

\section{Transit Alternatives and Characteristics}

The most common urban transit technologies typically include motor buses, light rail, and heavy rail (Canadian Urban Transit Association 1993). The most widespread technology of urban transit is the motor bus, which comes in several sizes (small rigid, standard rigid, and articulated), and its common use of shared right-of-way represents a clear cost advantage over transit technologies that require special supporting infrastructures. Urban buses may also operate on exclusive busways, and can provide local and express services.

Light rail represents another urban transit technology and provides a 
means of separating transit vehicles from other traffic. Light rail transit (LRT) embodies some benefits of rail transit in that it provides greater capacity and operates at relatively high speeds. At the same time, it may be implemented at a relatively low cost if the system shares readily available rights-of-way with other street traffic.

Heavy rail systems operate with full protection of the right-of-way, thus enabling high-speed operation and providing high line capacities with reasonable fleet size. In dense urban areas and city centers, right-of-way protection is typically provided by an underground alignment, with elevated and at-grade guideways also being common. Extensive supporting infrastructure is required for heavy rail to take advantage of the speed and capacity capabilities inherent in the technology. Such infrastructure includes high-level loading and offboard fare collection, thus resulting in relatively complex station structures.

\section{Evaluation Methods for Urban Transit Alternative}

This section examines several methods used to evaluate urban transit alternatives.

\section{Conventional Evaluation Methods}

In traditional, single-criterion evaluation methods, all benefits and costs are reduced to monetary terms. The present worth, annual cost, benefit to cost, and rate of return methods all fall into this category, since maximization of net benefits is the single objective of concern. However, transportation planning (including evaluation of urban transit alternatives) typically deals with many objectives that reflect the interest of the community (e.g., cost, capacity, level of service, and environmental impacts).

As such, the Multicriteria Evaluation Method may be used to address such cases. In this method, the planner defines a number of measures of effectiveness for system objectives, and then assigns values to each alternative based on collected data. With use of weighting factors for objectives, a composite score is determined for each alternative, with the alternative with the highest score being the preferred one (Khisty 1990; Janarthanan and Schneider 1986).

Two other techniques address the multicriteria and multiple-goal nature of urban transportation problems (Dickey 1983). In the Goals-Achievement 
Technique, each potential project alternative is assessed in terms of its impacts with respect to the proposed objectives. Quantitative measures are employed in this process, although some may be subjective and even probabilistic.

On the other hand, in the application of the Cost-Effectiveness Analysis, the attributes of the alternative are separated into two classes-costs and indicators of effectiveness, or the degree to which an alternative achieves the set objectives. The Cost-Effectiveness framework is useful in that it illustrates trade-offs between alternatives and identifies dominated systems.

\section{Other Evaluation Methods and Applications}

An evaluation of alternative transit system configurations that could best provide service in travel corridors within the Greater Milwaukee area is reported in Meyer and Miller (1983). Transit system plans were developed and then evaluated for each alternative future scenario based on measures of transit ridership, cost, and cost-effectiveness. A total of 21 plans were tested and evaluated, and the elements of the plans not meeting tests for cost-effectiveness were eliminated from further consideration, and the resulting "truncated" plans were then reevaluated.

An evaluation of high-speed rail alternatives along two main corridors in Greece combined three existing evaluation methods, namely financial analysis, cost-benefit analysis, and multicriteria analysis (Tsamboulas et al. 1992). Financial analysis was carried out at the first stage of the evaluation process to determine the commercial viability of the system to be executed, while cost-benefit analysis was carried out to quantify and evaluate the various impacts of the project from the national economic point of view. Moreover, since benefit-to-cost could only evaluate a single criterion, multicriteria analysis was used to overcome this difficulty and to account for nonquantifiable impacts. Evaluation criteria included transport, environmental, regional development, and safety considerations.

A different approach was adopted for providing technical support to decision-makers charged with evaluating transit technologies to be possibly implemented in British cities. The adopted approach attempted to capture the knowledge base of experts in cities in continental Europe regarding factors influenc- 
ing choice of public transport technology, and developed this experience into an expert system, a form of artificial intelligence (Mackett 1994). The knowledge base was designed to incorporate information regarding characteristics of transit technologies, systems used in different cities, and cost considerations.

Finally, multiattribute utility theory, a normative model of decision making, was used to evaluate different system designs and technologies associated with the emerging field of Advanced Public Transportation Systems (Reed et al. 1994). It is argued that multiattribute utility theory provides decision support in environments involving multiple, possibly conflicting, objectives by decomposing tasks, such as transit system design, into smaller issues and by requiring a priori elaboration of design objectives. In one presented example, the hierarchy for transit system design had system implementability, satisfaction, and affordability as overall objectives.

\section{AHP Evaluation: Background and Structur}

The AHP is a methodology for solving complex problems that involve many criteria using the knowledge, expertise, and judgment of the decisionmaker. By applying this technique to the transit system evaluation problem, transit planners are provided with a hierarchy in which all relevant factors are organized in a logical and systematic way from the goal to the factors and subfactors and down to the transit system alternatives. Moreover, it facilitates robustness analysis of the transit technology selection decision with respect to various judgments that are made in the selection process.

Expert Choice, an AHP-based decision analysis software, was used to conduct automated analyses of the designed hierarchy; the basic principles of AHP are covered in the literature (Saaty 1980; Skibniewski and Chao 1992). In the AHP evaluation procedure, planners of transit systems are asked to judge the elements of the hierarchy as to their relative importance. The judgments are made using pairwise comparisons on a one-to-nine numerical scale or its verbal equivalent. The pairwise comparisons are then synthesized to rank the alternatives from which the choice is to be made.

The strengths of AHP include its sound mathematical basis, its ability to integrate subjective judgments into the overall evaluation in a structured and 
consistent manner, and the possibility of incorporating both qualitative as well as quantitative decision criteria. While the AHP provides a unique decisionstructuring tool that ranks the alternatives being considered, it does not eliminate the need for conducting further analysis that may be warranted to, for example, assess the financial, economic, or environmental viability of the preferred alternative.

\section{The Evaluation Hierarchy}

This section examines the hierarchy proposed for the evaluation of urban transit systems.

\section{System Objectives}

In general, a transit system should achieve betterment in the urban transport picture and needs to mitigate possible implementation impediments. On the betterment side, transit systems are perceived to offer a wide variety of benefits; methods to measure such benefits have been suggested in the literature (see, for example, Horowitz and Beimborn 1995). A synthesis of the literature has resulted in adopting the following transit system objectives in the decisionstructuring and robustness analysis: appropriate level of service and performance, congestion reduction potential, support of economic development, and flexibility (Khisty 1990; Mackett and Edwards 1996).

On the other hand, mitigation of impediments requires that transit system objectives include cost control and cost effectiveness, environmental sensitivity, and implementability (Reed et al. 1994; Mackett and Edwards 1996). An elaboration of the AHP evaluation hierarchy is presented below in terms of system characteristics bearing on both betterment and impediment factors (Figure 1).

\section{Betterment Factors}

As indicated in the proposed evaluation hierarchy (Figure 1), transit system betterment factors include system level of service and performance, congestion relief potential, support of economic development, and system flexibility. The following discussion provides illustrations of specific factors by referring to urban transit systems relying on bus, light rail, and heavy rail technologies. 


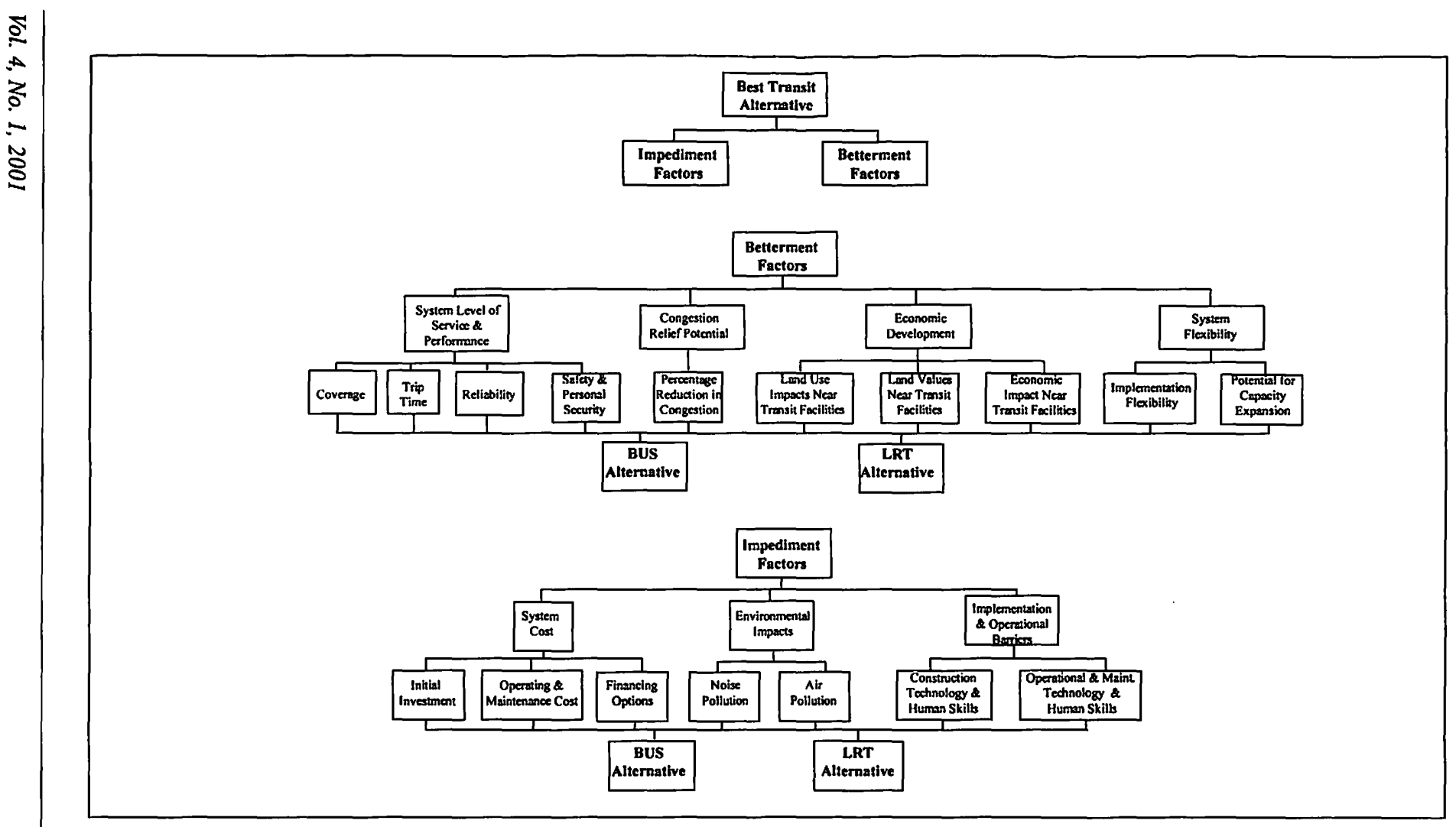


System Level of Service and Performance. Transit system level of service and performance may be related to coverage, trip time, system reliability, as well as safety and personal security concerns. Coverage reflects the area covered by the proposed network and typically includes activities lying within onequarter mile on either side of a transit line (see, for example, Khisty 1990). Trip time represents a significant determinant of transit level of service and is defined as the sum of the in-vehicle and out-of-vehicle time spent to make a certain trip. Total trip time consists of the walk or access time, wait time, station dwell time (loading and unloading), line-haul time (function of the vehicle speed), and egress time. As such, travel times for various urban transport modes depend on operational characteristics that relate to each of the components as evidenced by many studies. One study compared ride time and nonride time for the transitway (bus operating on reserved lane) and light rail, considering a typical route with feeder service at one end and with a connecting (distribution) service at the other end (Nisar and Khan 1992). The study concluded that, due to its more frequent service, the out-of-vehicle time and total trip time for the transitway were less than those for the LRT system. The impact of contra-flow and with-flow (reserved) lanes on travel times of buses and high-occupancy vehicles (HOVs) has also been the subject of research (Flachsbart 1989). Such operational measures have been found to have a significant impact on transit system level of service and its betterment capabilities.

In addition, system reliability has a bearing on the betterment rating of transit systems. One aspect of system reliability reflects the extent of variability in travel time from day to day. In general, transit modes that operate on an exclusive right-of-way provide more reliable service. Another important factor in this context relates to the power source for the transit system. If the system operates on fuel that is mainly imported, or on electric power, and shortages occur in either energy source, then system reliability may be compromised. Finally, safety and personal security on a transit system, being two factors influencing system level of service, are related to accident rates. There is evidence to indicate that the heavy rail transit (HRT) system is associated with a better safety record, followed by the LRT system, then the bus system (Khisty 
1990). Moreover, other evidence indicates that dedicated rights-of-way of HOV facilities are safer than non-HOV facilities as far as accident rates are concerned (ITE Technical Committee 6A-37 1988). In addition, studies have concluded that while the transitway and the LRT options are very good in securing personal safety, the LRT system, with the separated guideway and more controlled at-grade crossings, could be considered slightly safer (Nisar and Khan 1992).

Congestion Relief Potential. The betterment prospect of a transit system may also be related to its potential to reduce congestion in the corridor or travel context of concern, by capturing the maximum number of commuters in the peak hour. The expected ridership on a transit mode reflects the percentage of the peak flow that will be attracted and is a function of coverage, trip time, and headway of the transit system as well as the characteristics of competing modes (e.g., private auto and the jitney). Table 1 provides prototypical values of frequencies, headways, and capacities for a number of transit technologies

\begin{tabular}{|c|c|c|c|c|c|}
\hline \multicolumn{6}{|c|}{$\begin{array}{c}\text { Table } 1 \\
\text { Prototypical Transit System Frequencies and Capacities }\end{array}$} \\
\hline Mode & $\begin{array}{c}\text { Units } \\
\text { per Hour }\end{array}$ & $\begin{array}{l}\text { Vehicles } \\
\text { per Unit }\end{array}$ & $\begin{array}{l}\text { Headway } \\
\text { (seconds) }\end{array}$ & $\begin{array}{l}\text { Max. Passengers } \\
\text { per Vehicle }\end{array}$ & $\begin{array}{c}\text { Capacity } \\
\text { (passengers } \\
\text { per hour) }\end{array}$ \\
\hline \multicolumn{6}{|l|}{ Mixed traffic } \\
\hline Buses & 90 & 1 & 40 & 80 & 7200 \\
\hline Streetcars & 60 & 1 & 60 & 100 & 6000 \\
\hline \multicolumn{6}{|l|}{ Exclusive lanes } \\
\hline Buses & 120 & 1 & 30 & 80 & 9600 \\
\hline Streetcars & 75 & 2 & 48 & 100 & 15000 \\
\hline \multicolumn{6}{|l|}{ Busways } \\
\hline On-line stations & 180 & 1 & 20 & 80 & 14400 \\
\hline \multicolumn{6}{|l|}{ LRT } \\
\hline Rigid Cars & 30 & 6 & 120 & 100 & 18000 \\
\hline HRT & 30 & 9 & 120 & 160 & 43200 \\
\hline
\end{tabular}

Source: Adapted from Canadian Transit Handbook. 1993

Vol. 4, No. 1, 2001 
in different operational environments. (System headway is the time between two successive units in a transit system, and is directly related to frequency of service, waiting time, target system capacity, and required fleet size.)

Economic Development Impacts. In general, land-use impacts near transit facilities are manifested in commercial or residential developments that are attracted to locations close to transit stations. In Toronto, for instance, it was estimated that almost half of high-rise residential development was concentrated in four districts that all have good access to the city's subway (ITE Technical Committee 6A-37 1992). However, this process of development is not automatic since developers would only build new projects near a transit station under favorable circumstances including consumer demand and economic strength. Another factor in this context lies in the increase in land values near transit facilities due to the improved access to transit service and facilities. However, the process of increase in land values depends on the quality of service offered by the transit system (ITE Technical Committee 6A-37 1992) and, in some cases, transit stations may have negative impacts on residential land values due to parking and congestion problems near transit stations.

Moreover, economic impacts near transit facilities represent another potential betterment dimension of transit facilities. In general, urban rail transit promotes efficient metropolitan travel and provides an appropriate environment for economic development, possibly in the form of increased area employment opportunities, quicker travel to retail centers, and location of large office complexes near stations. Such development typically results in a broader community tax base including income, sales, business, and real estate taxes (ITE Technical Committee 6A-37 1992).

System Flexibility. The two main factors characterizing transit system flexibility relate to implementation flexibility and the potential for capacity expansion. The possibility of the transit technology option being implemented in phases bears positively on the system flexibility rating and provides system planners with the ability to customize system design to cater to travel needs on a staged basis. This may be the case, for instance, with dedicated rights-of-way that may be first used for busways and later for light rail. Moreover, a desir- 
able quality of a transit system relates to the potential for capacity expansion that leaves room for incrementally introducing system capacity and/or expanding the system at a future date. For instance, light rail projects may benefit from incremental development and enhancement of service which takes the form of double-tracking single track lines, adding new vehicles, expanding the power system, line extension, and grade separation at important intersections (Larwin 1989).

\section{Impediment Factors}

As indicated in the proposed evaluation hierarchy (Figure 1), transit system impediment factors include system cost, environmental impacts, and implementation and operation barriers. The discussion presented below provides illustrations of specific factors by referring to urban transit systems relying on bus, light rail, and heavy rail technologies.

System Cost and Financing. The initial investment or capital cost of a transit system includes the total price of the fleet of vehicles to be purchased, in addition to the money required to implement the infrastructure needed. The required fleet size is determined based on target system capacity. As such, cost per transit vehicle and cost per kilometer of infrastructure needed constitute the major determinants of capital cost. Service life of a transit asset, defined as the number of years after which it would be no more economical to keep operating the asset, is an important factor that has to be considered in estimating capital renewal costs of different transit technologies. Another component of system costs consists of operating and maintenance costs required to operate and maintain transit equipment, in addition to maintenance of the right-of-way. Unit operating costs per hour of service and per kilometer of service are typically used to estimate time- and distance-based variables or operating costs in transit systems.

Research and available literature (Canadian Urban Transit Association 1993; Dickey 1983; Nisar and Khan 1992; Parody et al. 1990) provide reference values for various system cost aspects including:

- prototypical costs per vehicle and per infrastructure unit;

- operating and maintenance costs for diesel bus and LRT; 
- operating and maintenance expenses and total passenger-miles for bus and subway systems in North America;

- annual operating and maintenance costs for four different rapid transit systems in one English city;

- and economic life for the motor bus, diesel bus, light rail vehicle, heavy rail vehicle, and various other transit assets.

The financing burden of transit systems constitutes another impediment factor. Financing options for transit systems include charges on benefiting properties, joint ventures with the private sector, and marketing and merchandising approaches (Johnson and Hoel 1987; ITE Technical Committee 6Y-33 1988). The extent to which transit system financing constitutes an impediment is related to the differential possibilities offered by various transit system technologies with respect to financing techniques falling within each of the above categories of options.

Environmental Impacts. In many urban areas, transportation is a major source of noise. Hence, excessive noise can lower the quality of life for many, and can seriously interfere with sleep causing stress and, indirectly, stressrelated diseases. As such, noise pollution is introduced in the evaluation hierarchy as an impediment factor with differential values for competing modes. Moreover, since air pollutants emitted from engines of transit vehicles may have significant adverse effects on air quality both on a regional and local scale, air pollution is considered as another environmentally oriented impediment factor. Again, available literature (for example, Khisty 1990; Dickey 1983; Flachsbart 1989; Wayson and Bowlby 1989) provides reference values for engine noise from diesel operation, noise from LRT and HRT (dominated by noise from wheel/rail interaction), commuter exposure to motor vehicle exhaust, and relative capability of the bus, LRT, and HRT to reduce air pollution impacts.

Implementation and Operational Barriers. The basis on which the transit alternatives will be ranked with respect to construction technology and human skills involves the length of time for construction implementation, 
whether the construction technology is imported or locally available, and if imported, whether the technology is too sophisticated for implementation by local workers. For instance, with a bus-oriented transit system, expertise is usually available locally for construction of highways and bus terminals and facilities. On the other hand, the construction sector in many countries may not be prepared to handle projects involving LRT or HRT, especially if tunnels and other underground structures are required. Similar questions have to be posed with respect to operation and maintenance technology and human skills. Are technologies locally available? Are vehicles and routes to be maintained frequently? How much does it cost to import the technology and the human skills? Can the local population be readily trained to operate and maintain the new technology?

\section{Integration with the Political Environment}

The hierarchy presented in Figure 1 provides a solid basis for integrating the AHP-based transit alternatives evaluation approach with the political environment. While the input has to be primarily technical at the system (lowest) level, the hierarchy calls for public input in addition to technical judgments at the subcriteria (second lowest) level. In this regard, public participation meetings can help provide input with respect to relative weights of subcriteria which have a direct bearing on the end-user, such as those below the "System Level of Service and Performance" criterion. Moreover, the task of weighing the decision criteria under the "Betterment" and "Impediment" factors should reflect political priorities prevailing in the selection of viable transit alternatives. Finally, the decision structuring inherent in the proposed AHP-based approach ensures transparency in the decision-making process, a desirable objective in similar undertakings.

\section{Illustrative Example}

To illustrate how the proposed evaluation is performed, a prototypical application involving the selection of an appropriate transit technology for a commuter corridor in the City of Beirut, Lebanon, is considered. The Ministry of Transportation in Lebanon has commissioned a feasibility study to evaluate the possibility of utilizing an old coastal rail right-of-way to provide modern 
mass transit services between the towns of Jounieh and Jiyeh, passing through the City of Beirut. The proposed system is expected to become an integral element in a multimodal alternative to the auto-only transportation environment that currently dominates Greater Beirut. To enhance its chances of success, the mass transit system will provide park-and-ride facilities and will integrate with feeder systems of public and private bus services (IBI Group 2000).

The problem of selecting between the bus (operating mostly as bus rapid transit) and LRT technologies for this corridor is considered. For this purpose, the decision-support software Expert Choice is used. Information on the properties of the bus and LRT systems is assimilated from the literature referred to in the previous sections and used, with adjustments to reflect local conditions when appropriate, in the evaluation process (Table 2).

The first step in the process is to build a well-defined evaluation hierarchy that formulates the decision problem and defines its different levels

\begin{tabular}{|ccc|}
\hline \multicolumn{2}{|c|}{$\begin{array}{c}\text { Table } 2 \\
\text { Input Data Used for Setting Out Priorities }\end{array}$} & LRT \\
\hline & Bus & 25 \\
\hline Coverage (sq. miles) & 30 & 57.9 \\
\hline $\begin{array}{c}\text { Trip time (min.) } \\
\text { Safety (\%) }\end{array}$ & 50.4 & 20 \\
\hline $\begin{array}{c}\text { Pollution noise level } \\
\text { (DBA) }\end{array}$ & 15 & 87 \\
\hline $\begin{array}{c}\text { Air pollution } \\
\text { reduction (\%) }\end{array}$ & 90 & 30 \\
\hline \begin{tabular}{c} 
Congestion relief (\%) \\
\hline
\end{tabular} & 20 & 27 \\
\hline
\end{tabular}


(Figure 1). Next, the hierarchy model is input into the software database, creating an Expert Choice model (Figure 2). This model organizes the various elements of the problem into a hierarchy or tree. Each element in the tree is called a node. The top level contains the goal, whereas intermediate levels represent factors affecting that goal. The bottom level contains the alternatives of choice.

Once the Expert Choice model is built, the following step consists of evaluating the criteria. Instead of assigning weights or priorities that may be arbitrary and difficult to justify, Expert Choice helps the decision-maker apply data, knowledge, and experience to derive priorities. Evaluation, or weighing of the different criteria, is accomplished by performing pairwise comparisons. Pairwise comparison may be expressed in terms of importance, preference, or likelihood. For example, the decision-maker compares the relative importance of the criteria with respect to the goal and compares the relative preference of the alternatives with respect to each objective.

To facilitate the weighting process, Expert Choice runs a questionnaire that asks the decision-maker to make a judgment on the elements under the same parent node. Figures 3 through 5 show the questionnaires provided by the software and the decision-maker's weighting of elements under the goal (Figure 3), impediment (Figure 4), and system cost nodes (Figure 5). In Figure 3, for instance, the judgment entered (value of 1.0) indicates an equal importance for "betterment" and "impediment" with respect to the overall "goal." Moreover, Figure 6 illustrates the relative preference indicated by the decision-maker in ranking the two alternatives under the initial investment node, with a value of 9.0 indicating a very high preference for bus. This arrangement makes it possible for decision-makers to focus on each and every part of the complex problem, and to derive "local" priorities (relative priorities of factors with respect to the next higher-level factor). Expert Choice also tests the consistency of comparisons and helps the user improve it by providing an inconsistency measure.

Arrays of criteria weights and of alternatives weights are generated for each level of the hierarchy as a result of the pairwise comparison. A final priority ranking at the lowest level is then determined by backward multiplication (performed by the software) of the transformation matrices of all levels. The software then synthesizes or combines the "local" priorities to obtain "global" 


\section{TRANSIT SYSTEMS EVALUATION FOR THE CITY OF BEIRUT}

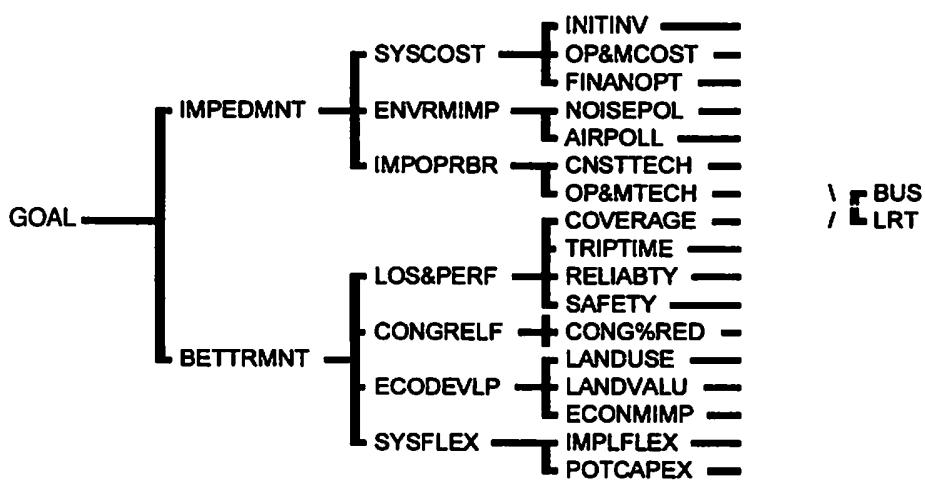

\begin{tabular}{|c|c|}
\hline Abbreviation & Definition \\
\hline \multicolumn{2}{|l|}{ GOAL } \\
\hline$\overline{A I R P O L L}$ & AIR POLLUTION \\
\hline BETTRMNT & BETTERNENT FACTORS \\
\hline BUS & BUS ALTERNATVE \\
\hline CNSTTECH & CONSTRUCTION TECHNOOOGY AND HUMAN SKILLS \\
\hline CONG\%RED & PERCENTAGEE REDUCTIONIN CONGESTION \\
\hline CONGRELF & CONGESTION RELEF POTENTIAL \\
\hline COVERAGE & COVERAGE \\
\hline ECODEVLP & ECONOMIC DEVELOPMENT \\
\hline ECONMIMP & ECONOMIC IMPACTS NEAR TRANSTI FACILITIES \\
\hline ENVRMIMP & ENVIRONMENTAL IMPACTS \\
\hline FINANOPT & FINANCNG OPTIONS \\
\hline IMPEDMNT & IMPEDIMENT FACTORS \\
\hline IMPLFLEX & IMPLEMENTATION FLEXIBILITYY \\
\hline IMPOPRBR & IMPLEMENTATION AND OPERATIONAL BARRIERS \\
\hline INITINV & INITIAL INVESTEMENT \\
\hline LANDUSE & LAND-USE IMPACTS NEAR TRANSIT FACILITIES \\
\hline LANDVALU & LAND VALUE NEAR TRANST FACILITIES \\
\hline LOS\&PERF & SYSTEM LEVEL OF SERVICE \& PERFORMANCE \\
\hline$\overline{\text { LRT }}$ & LIGHT RAIL TRANST \\
\hline NOISEPOL & NOISE POLLUTION \\
\hline OPAMCOST & OPERATING AND MAINTENANCE COST \\
\hline OP\&MTECH & OPERATION \& MAINTENANCE TECHNOOOGY AND HUMAN SKILLS \\
\hline POTCAPEX & POTENTLAL FOR CAPACTY EXPANSION \\
\hline RELIABTY & RELIABILITY \\
\hline SAFETY & SAFETY \& PERSONAL SECURTY \\
\hline SYSCOST & SYSTEM COST \\
\hline SYSFLEX & SYSTEM FLEXBBIUTY \\
\hline TRIPTRME & TRIPTIME \\
\hline
\end{tabular}

Figure 2. Complete unweighted AHP diagram 


\section{TRANSIT SYSTEMS EVALUATION FOR THE CITY OF BEIRUT}

Compare the relative IMPORTANCE with respect to: GOAL <

Circle the more IMPORTANT element and indicate how many times more IMPORTANT it is in the intensity column (enter 1.0 for equality).

Intensity

\begin{tabular}{|l|l|l|}
\hline 1 & IMPEDMNT & BETTRMNT \\
\hline
\end{tabular}

Questionnaire

\begin{tabular}{|l|l|}
\hline \multicolumn{1}{|c|}{ Abbreviation } & \multicolumn{1}{c|}{ Definition } \\
\hline Goal & TRANSIT SYSTEMS EVALUATION FOR THE CITY OF BEIRUT \\
\hline IMPEDMNT & IMPEDIMENT FACTORS \\
\hline BETTRMNT & BETTERMENT FACTORS \\
\hline
\end{tabular}

IMPEDMNT .500

BETTRMNT .500

Inconsistency Ratio $=0.0$

Evaluation/Data

Figure 3. Evaluation of elements under goal node 
or overall priorities (relative priorities of factors with respect to the goal) for the alternatives at the lowest level of the tree. For example, with respect to being an impediment to the adoption of a certain transit system, the system cost factor, among the impediments, has a local priority of 0.627 , which is higher than those of the other factors (Figure 7). This resulted from the comparisons given in Figure 4 with the system cost factor judged to be 5.0 times more important than the environmental impact, and 3.0 times more important than implementation and operational barriers. In turn, the higher calculated priority indicates a greater contribution by this factor to the final decision.

The AHP results synthesized at the subfactor and alternative levels for the betterment and impediment subhierarchies are presented in Figure 8 . Figure 8 refers to the global priorities that represent the portion of the priorities inherited by the various nodes. From the judgments used in this example, the synthesis of the evaluation with respect to the goal yielded a priority of 0.557 for the bus alternative compared to a priority of 0.443 for the LRT alternative, indicating that the former is slightly more preferred to the latter.

\section{Robustness Analysis}

Extensive analysis was performed to study the robustness of the results with respect to the input judgments used. The global priorities of 0.557 and 0.443 generated at the goal level are based on equal weights given to both the negative (impediment) and the positive (betterment) factors as well as on specific relative priorities judged to hold for factors lying at each branch and level of the hierarchy. The robustness of urban transit technology decision to changes in relative priorities of factors under the impediment subhierarchy is considered next. The influence of a change in the importance of the system cost factor is illustrated in Figure 9. The bus alternative is preferred more than the LRT alternative for higher priorities of the system cost factor, whereas the preference level decreases for lower priorities. However, the slopes of the goal priorities are not steep enough to intersect and, thus, induce a change of preference between the two choices (i.e., the bus alternative will be always preferred to the LRT alternative). Moreover, the decision was found to be somewhat sensitive to relative priority of the environmental impact criterion. While the base 


\section{TRANSIT SYSTEMS EVALUATION FOR THE CITY OF BEIRUT}

Compare the relative IMPORTANCE with respect to: IMPEDMNT < GOAL

Node: 10000

For each row, circle the more IMPORTANT element and indicate how many times more IMPORTANT it is in the intensity column (enter $\mathbf{1 . 0}$ for equality).

Intensity

\begin{tabular}{|l|l|l|}
\hline 1 & SYSCOST & ENVRMIMP \\
\hline 2 & SYSCOST & IMPOPRBR \\
\hline 3 & ENVRMIMP & IMPOPRBR \\
\hline
\end{tabular}

\section{Questionnaire}

\begin{tabular}{|c|c|c|}
\hline & ENVRMIMP & IMPOPRBR \\
\hline SYSCOST & 5.0 & 3.0 \\
\hline ENVRMIMP & & $(4.0)$ \\
\hline
\end{tabular}

Row olemonl is _timos moro than colsmn olement unless enclosed in ( )

\begin{tabular}{|l|l|}
\hline \multicolumn{1}{|c|}{ Abbraviation } & \multicolumn{1}{c|}{ Definition } \\
\hline Goal & TRANSIT SYSTEMS EVALUATION FOR THE CITY OF BEIRUT \\
\hline IMPEDMNT & IMPEDIMENT FACTORS \\
\hline SYSCOST & SYSTEM COST \\
\hline ENVRMIMP & ENVIRONMENTAL IMPACTS \\
\hline IMPOPRBR & IMPLEMENTATION AND OPERATIONAL BARRIERS \\
\hline
\end{tabular}

\section{SYSCOST $\quad .627$}

ENVRMIMP .094

IMPOPRBR .280

Inconsistency Ratio $=0.08$

Evaluation/Data

Figure 4. Evaluation of elements under impediment node 


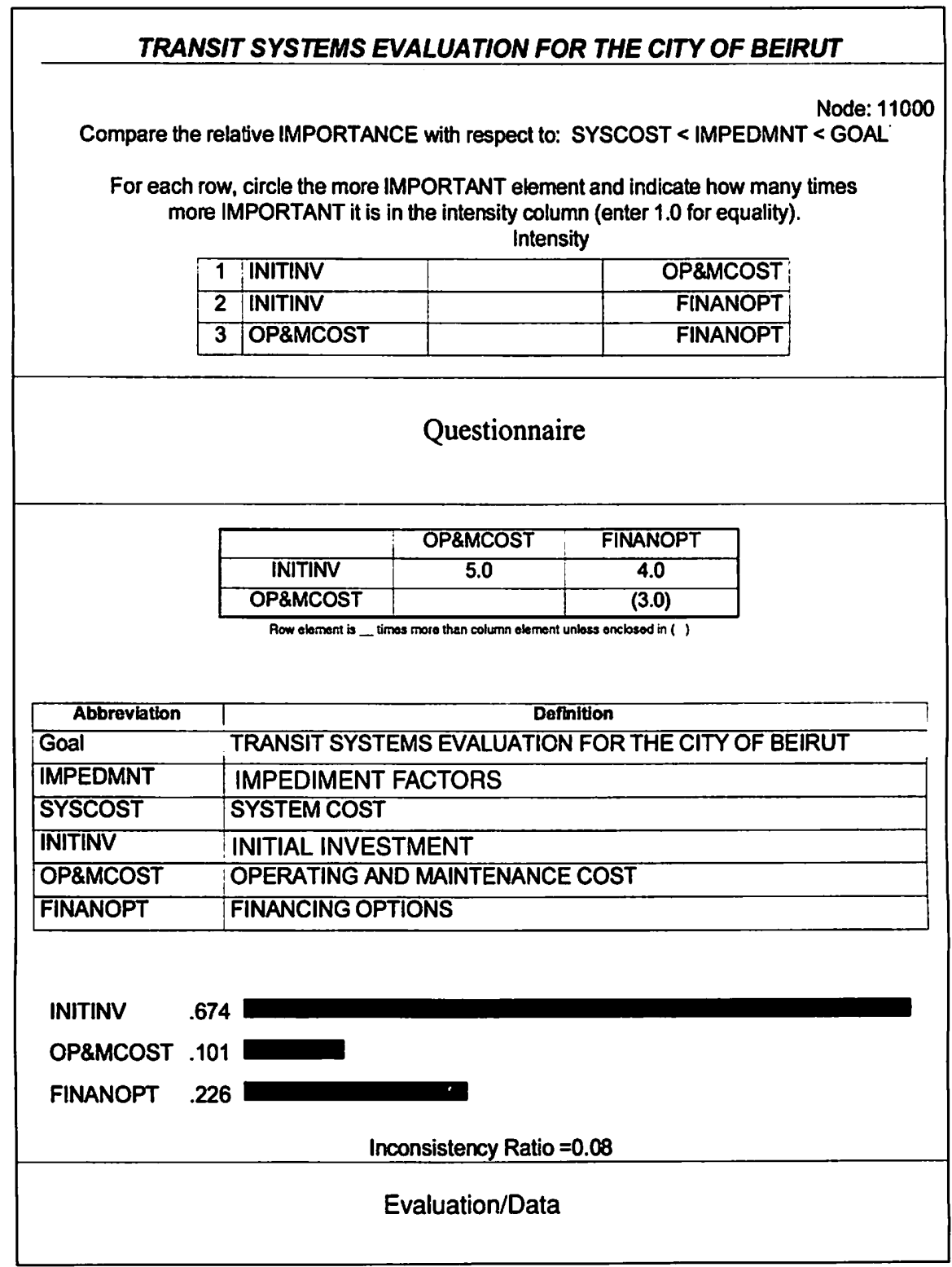

Figure 5. Evaluation of elements under system cost node 


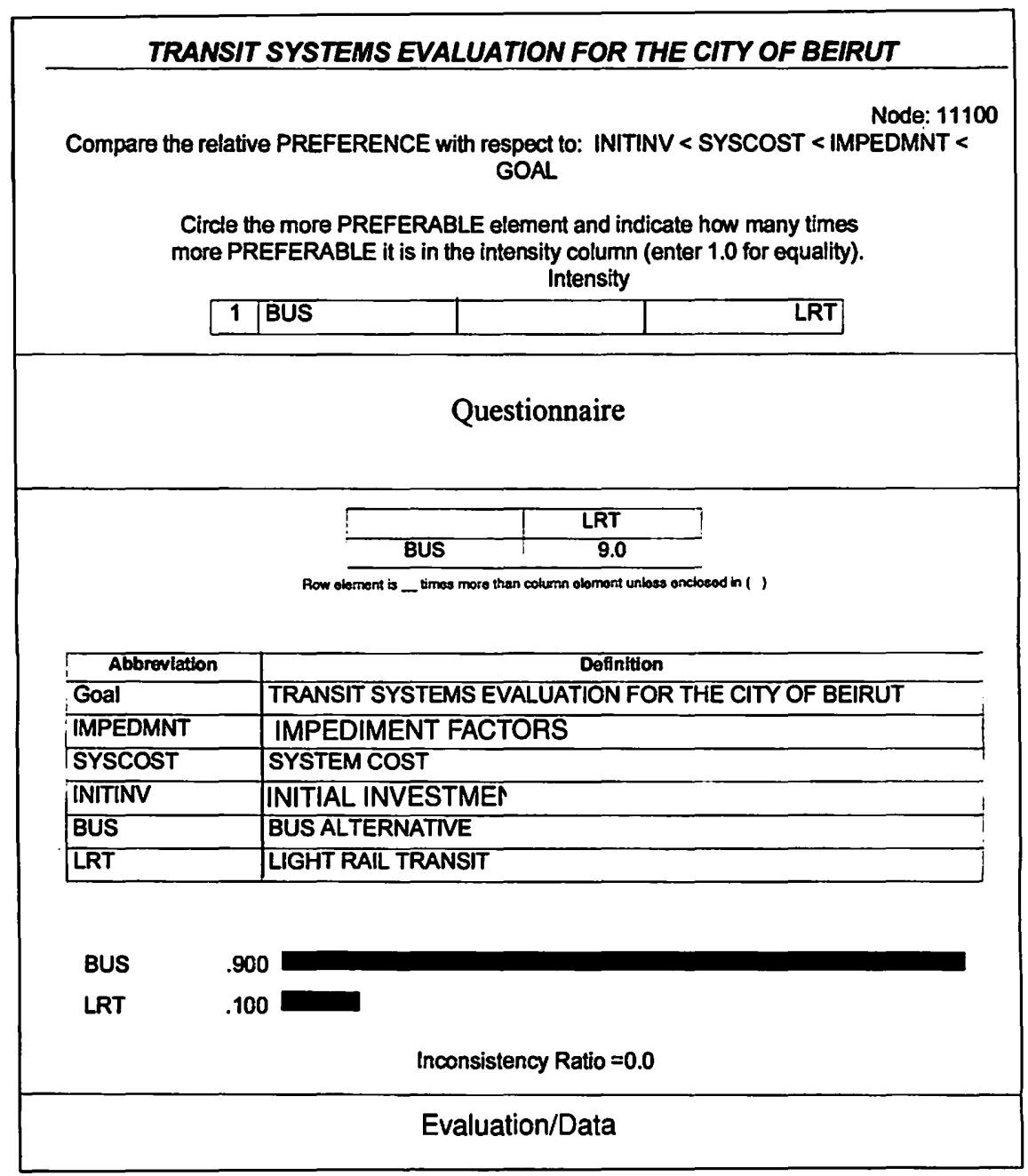

Figure 6. Alternatives preference regarding initial investment 


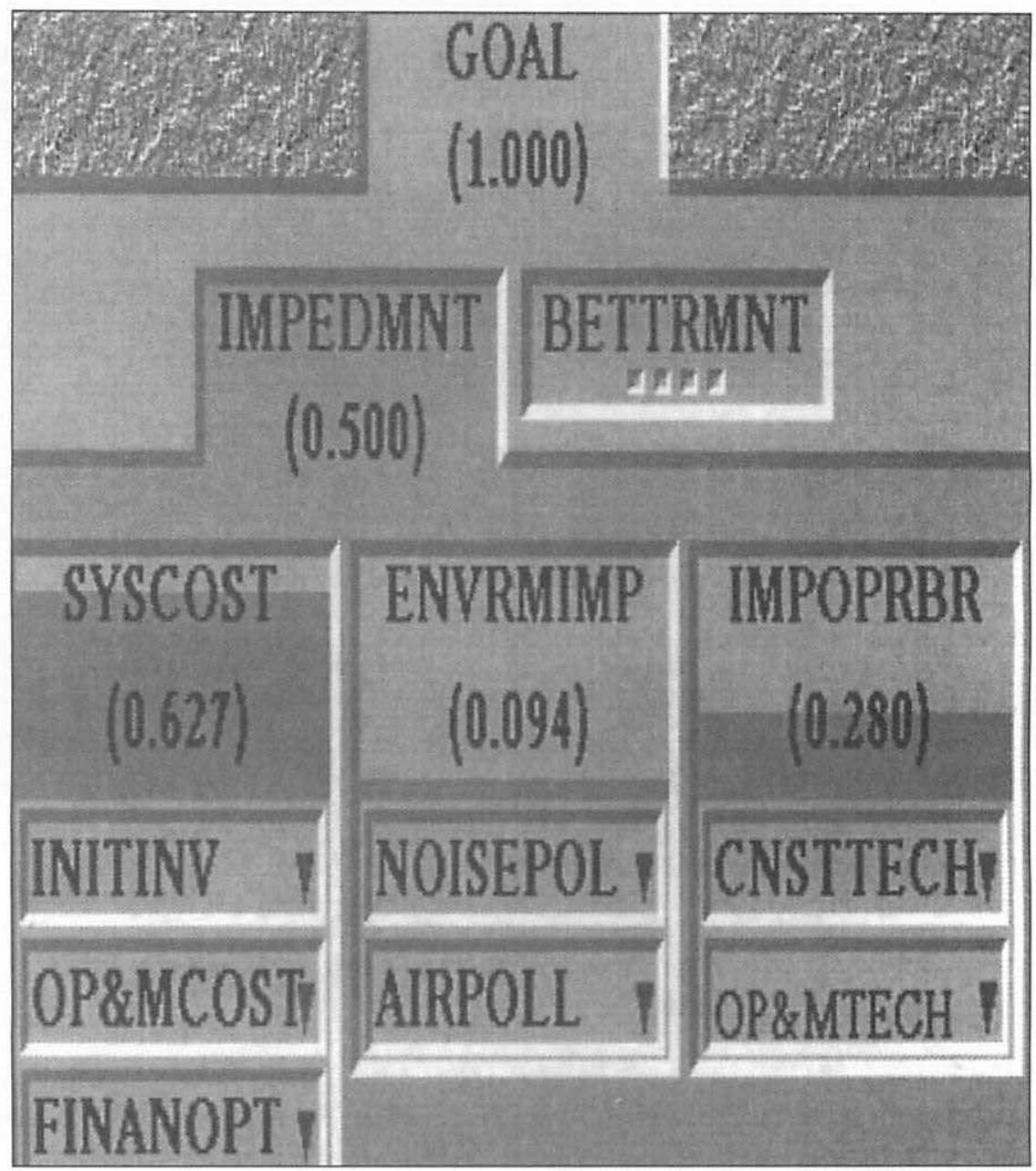

Figure 7. Local priorities under impediment node 


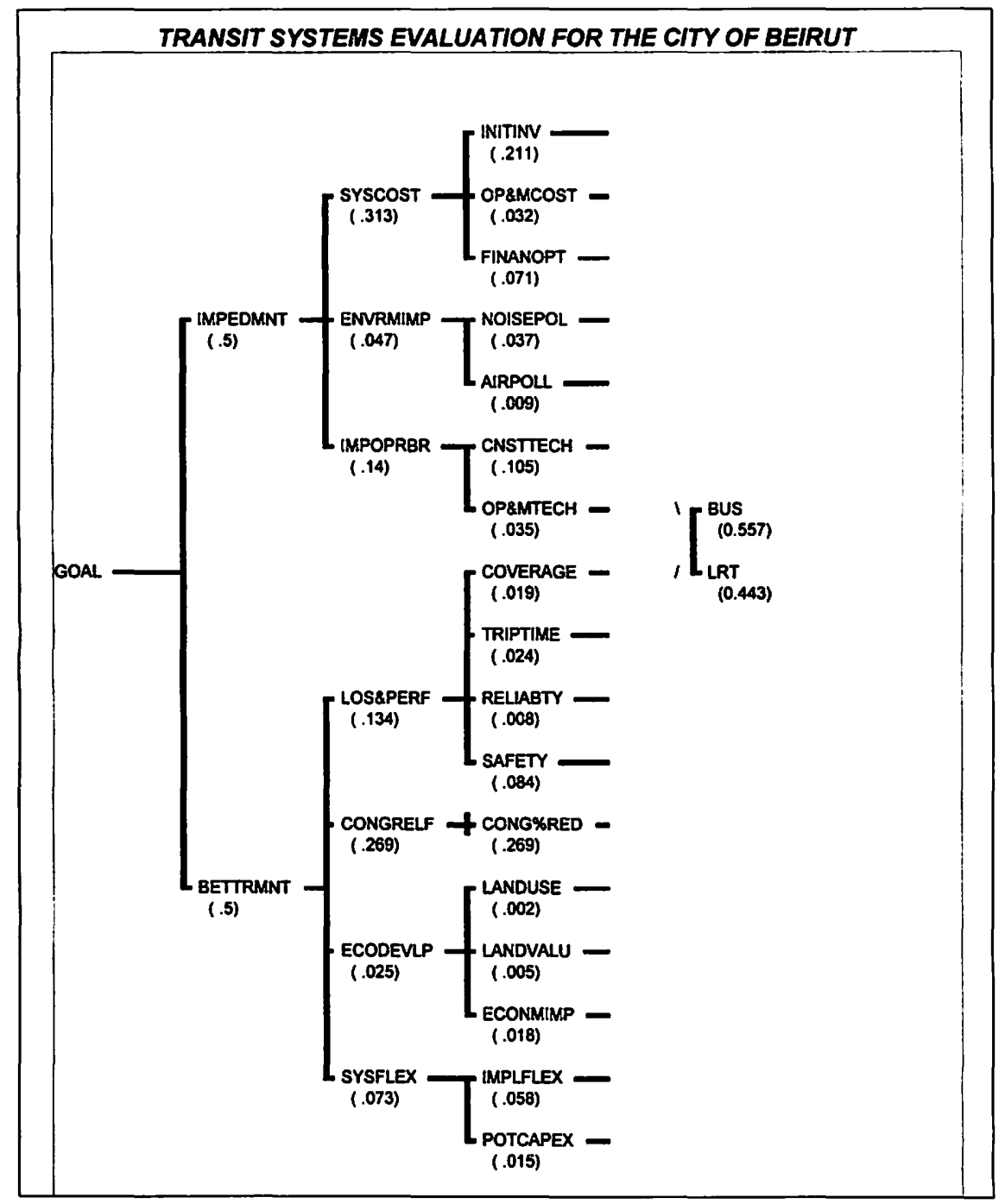

Figure 8. Global priorities for full AHP model 


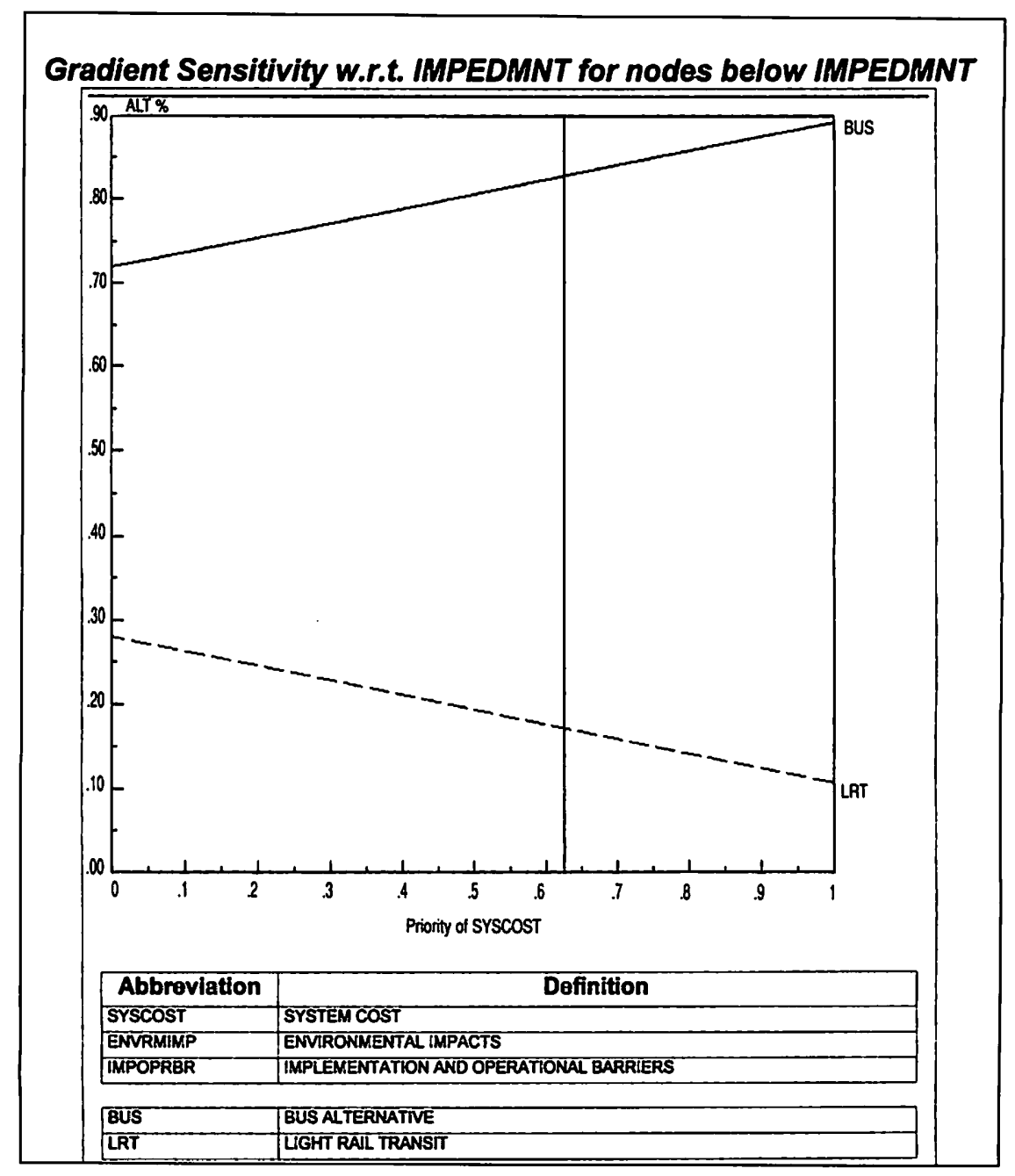

Figure 9. Sensitivity with respect to importance of "system cost" 
priority for the environmental impact criterion among impediment factors is 0.094, the model indicated that there would be a change of preference between the two urban transit alternatives at 0.73 priority value (Figure 10). In other words, if decision-makers judge environmental impacts to have such a high priority compared to system cost as well as implementation and operational barriers, the LRT alternative would then be preferred. Finally, the urban transit technology decision was found to be completely robust with respect to the relative importance of the implementation and operation barrier criterion.

Figure 11 presents the sensitivity of the final decision with respect to priorities at the top level. In the base case of equal priorities for betterment and impediment factors, bus is preferable to LRT. However, Figure 11 indicates that when the priority of impediments decreases to about 0.38 , the two alternatives become equally preferable, and the LRT is, in fact, preferred for impediment priorities lower than this value. This analysis indicates that the decision will hinge on the specific context-whether betterment is determined to be more critical for the urban area under consideration or, on the other hand, impediments represent a heavier constraint on urban transit development. When the priority of the impediments decreases (to 0.38 , for instance), the implication is that decision-makers have judged the need to achieve betterment in the urban transport context to overweigh significantly the challenges expected to be posed by any associated impediments. The approach being proposed, capitalizing on logical structuring of decision elements and factors, is wellsuited to handle similar robustness considerations.

\section{Conclusions}

The evaluation of urban transit alternatives has to take into consideration several objectives that reflect the interest of the community, such as cost, capacity, level of service, and environmental impacts. In this article, a framework for structuring the process of transit system evaluation has been proposed. It incorporates a number of criteria identified to be significant in the transit system planning process. The incorporated criteria are analyzed using the AHP evaluation approach and employing documented relevant characteristics of transit systems and technologies. The proposed approach is character- 


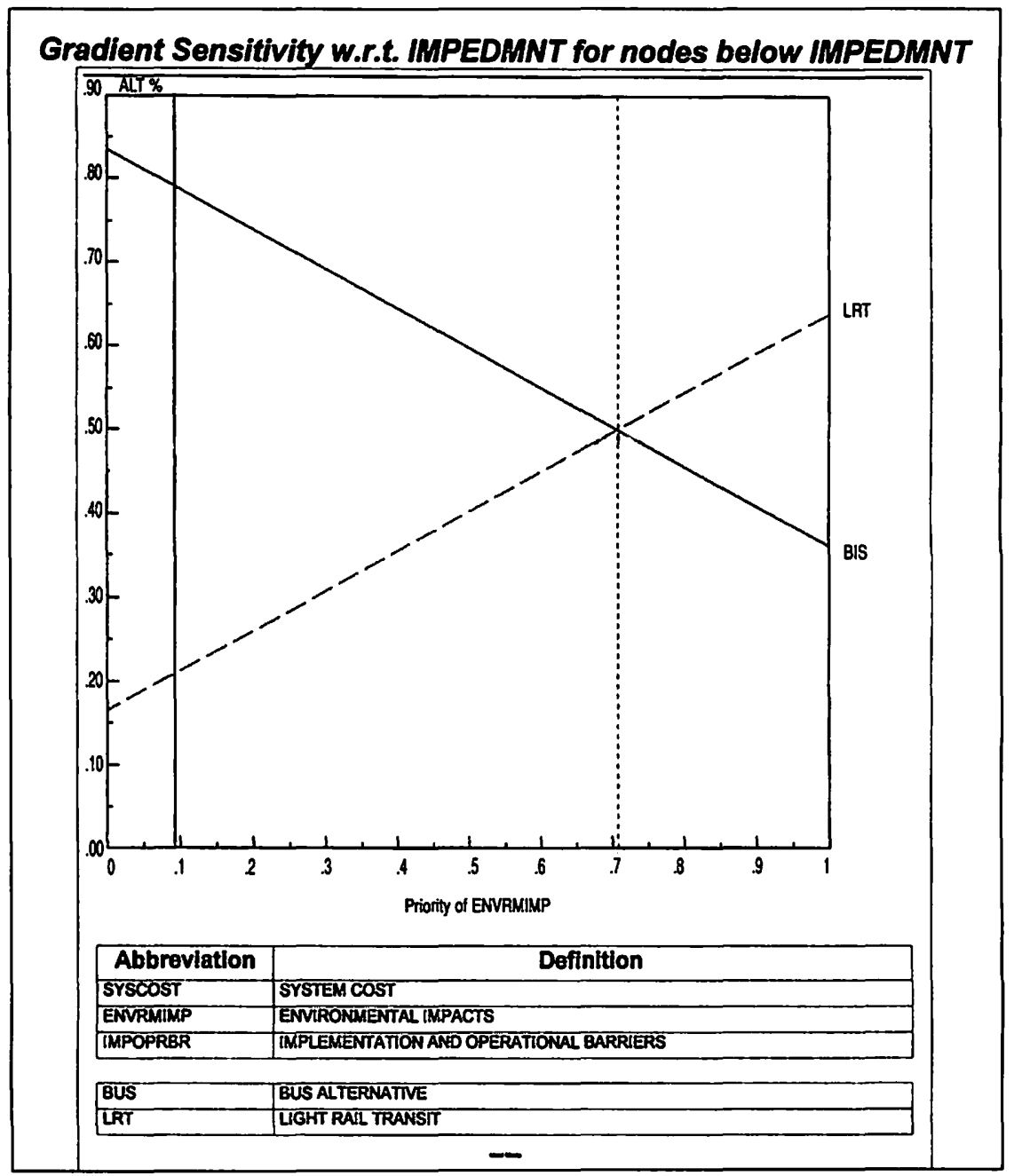

Figure 10. Sensitivity with respect to importance of "environmental impacts" 


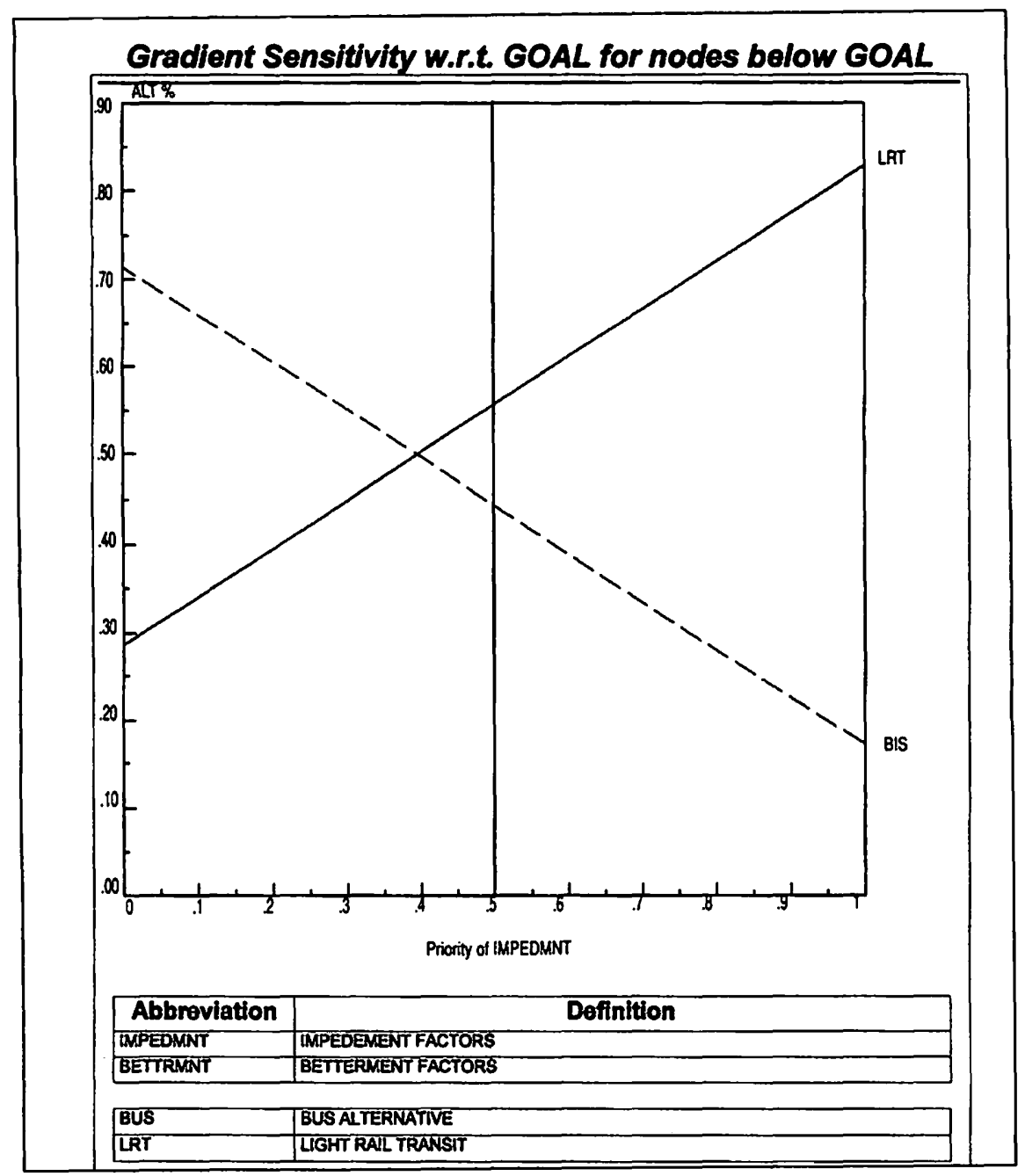

Figure 11. Sensitivity with respect to priority of "impediments" 
ized by its flexibility as far as hierarchy structure and judgments which may reflect the salient features of different urban transport contexts. As demonstrated above, this approach is quite helpful in decision structuring for selecting among urban transit alternatives. Moreover, it provides the facility of analyzing the robustness of the decision with respect to various judgments that are made in the proposed selection process. Finally, the methodology presented in this article aims at addressing the transit evaluation process at the strategic planning level and does not preclude the necessity to carry out life-cycle analysis incorporating costs and benefits relevant to the recommended transit system.

\section{Acknowledgments}

Financial support of this work by the University Research Board of the American University of Beirut is gratefully acknowledged. Thanks are also due to former and current graduate students Mireille Abdallah, Dany Chakour, and Donald Choubassi for their assistance in this research work.

\section{References}

Canadian Urban Transit Association. 1993. The Canadian transit handbook. 3rd ed. Toronto, Canada.

Dickey, J. 1983. Metropolitan transportation planning. New York: Hemisphere Publishing Corp.

Flachsbart, P. G. 1989. Effectiveness of priority lanes in reducing travel time and carbon monoxide exposure. ITE Journal: 4l-45.

Horowitz, A., and E. Beimborn. 1995. Methods and strategies for transit benefit measurement. Transportation Research Record 1496: 9-16.

IBI Group. 2000. Beirut suburban mass transit corridor feasibility study: Ridership and freight analysis. Beirut, Lebanon: Ministry of Transport.

ITE Technical Committee 6A-37. 1988. A summary report: The effectiveness of highoccupancy vehicle facilities. ITE Journal: 17-18.

ITE Technical Committee 6A-37. 1992. A summary of an ITE informational report: Impacts of transit facilities on land use. ITE Journal: 37-39.

ITE Technical Committee 6Y-33 (1988). Private financing of transportation improvements. ITE Journal: 43-51.

Janarthanan, N., and J. Schneider. 1986. Multicriteria evaluation of alternative transit system designs. Transportation Research Record 1064, TRB: 26-34. 
Johnson, G., and L. Hoel. 1987. Review of financing options for highways and transit. Journal of Transportation Engineering 113 (1): 72-83.

Khisty, J. 1990. Transportation engineering-An introduction. Englewood Cliffs, NJ: Prentice Hall.

Larwin, T. 1989. San Diego's light rail system: A success story. ITE Journal: 19-20. Mackett, R. 1994. Determining appropriate public transport system for a city. Transportation Research Record 1451: 44-50.

Mackett, R., and M. Edwards. 1996. Guidelines for planning a new urban public transport system. Proceedings of the Institution of Civil Engineers-Transport 117 (3): 193-201.

Meyer, M., and E. Miller. 1983. Urban transportation planning-A decision-oriented approach. New York: McGraw-Hill.

Newman, P., and J. Kenworthy. 1999. The costs of automobile dependence: A global survey of cities. In Transportation Research Record 1670: 17-26.

Nisar, M., and A. M. Khan. 1992. Transitway: An innovation in public transportation. ITE Journal: $35-39$.

Parody, T. E., M. E. Lovely, and P. S. Hsu. 1990. Net costs of peak and offpeak transit trips taken nationwide by mode. Transportation Research Record 1266: 139-144.

Reed, T., C. White, M. Bolton, and W. Hiller. 1994. Application of multiattribute utility theory to public transit system design. Transportation Research Record 1451: $37-43$.

Saaty, T. 1980. The analytical hierarchy process: Planning, priority setting, resource allocation. London, England: McGraw-Hill.

Skibniewski, M., and L. Chao. 1992. Evaluation of advanced construction technology with AHP method. Journal of Construction Engineering and Management 118 (3): 577-593.

Tsamboulas, D., S. Lioukas, and C. Dionelis. 1992. Evaluating alternative scenarios for high-speed rail investment in Greece. Transportation 19: 245-265.

Wayson, R., and W. Bowlby. 1989. Noise and air pollution of high-speed rail systems. Journal of Transportation Engineering 115 (1): 21-36. 


\section{About the Authors}

IsAM KAYSI (isam@aub.edu.lb) is an associate professor in the department of Civil and Environmental Engineering at the American University of Beirut.

Mohamed-Asem U. Abdul-MaLAK (mamalak@aub.edu.lb) is an associate professor in the Engineering Management Program at the American University of Beirut 